Studies in African Linguistics

Volume 25, Number 1, Spring 1996

\title{
BOUNDARY TONES AND THE PHONETIC IMPLEMENTATION OF TONE IN CHICHEWA*
}

\author{
Scott Myers \\ University of Texas at Austin
}

In Chichewa (Bantu, Malawi), there are three differences in fundamental frequency ( $\mathrm{f} O$ ) between questions and statements: (a) questions have a final rise, while statements have a final fall, (b) questions do not display the strong downdrift trend found in statements, and (c) questions are produced in a higher pitch range than statements. A quantitative model is proposed that captures these generalizations through a dependency of the bottom of the current pitch range on the boundary tone. It is argued that such a model accounts for the distinction between question and statement better than a model in which pitch range distinctions are encoded in the phonological representation.

\section{Introduction}

In Chichewa, a Bantu tone language spoken mainly in Malawi [N.31 in Guthrie 1967], yes/no questions can be distinguished from statements by means of fundamental frequency (f0) alone. ${ }^{1}$ A question differs from a statement in $\mathrm{f0}$ in three different ways: terminal pitch excursion, downdrift, and pitch range. All

\footnotetext{
* I would like to thank my language consultants Grant Sochera, Janet Banda, William Maseko, Patrick Soko, Din Balakasi, and Smith Likongwe. Zikomo kwambiri! Thanks also to the following people for helpful comments: Mark Liberman, Lisa Selkirk, Will Leben, Robert Botne, an anonymous $S A L$ reviewer, and audiences at the 26th Annual Conference on African Linguistics, the University of Sydney, the University of Western Australia, Stanford University, and University of Texas.

1 All questions considered in this study are yes/no questions, since WH-questions necessarily involve differences in segmental material between the question and the corresponding statement. WH-questions in the mini-dialogues sometimes displayed the statement pattern described below, and sometimes were like yes/no questions, with a great deal of variation both within and between speakers. Henceforth, therefore, the term "question" refers in this paper exclusively to yes/no questions.
} 
three of these differences reflect patterns that are well-attested crosslinguistically.

Questions in Chichewa have a sharp rise in f0 in the final syllable of the utterance, while statements end in an fO fall. Such a contrast in terminal pitch excursion is extremely wide-spread across languages [Bolinger 1978]. Pierrehumbert [1980] represents such excursions with boundary tones, which are intonational tones that are aligned with the edge of a prosodic phrase.

Downdrift is the pattern in which each successive pitch peak in a phrase is lower than the previous one. Statements in Chichewa display a strong downdrift effect, but this tendency is much less strong in questions. There is significantly less of a downward trend in questions than in statements in a wide variety of languages: English [O'Shaughnessy 1979:139; Uldall 1962:780], Swedish [Hadding-Koch and Studdert-Kennedy 1964], Hausa [Inkelas and Leben 1990], Danish [Thorsen 1978:168], Mandarin [Gårding 1987], and Zulu [Rycroft 1963:47].

Pitch range is the range of values between the highest and lowest $f 0$ values in a given stretch of speech. In a higher pitch range, both the peaks and the troughs are higher than in a lower pitch range. In Chichewa, the peaks are higher in questions than in statements. Such an effect has been observed in a number of languages: English [O'Shaughnessy 1979:139; Uldall 1962:780], Swedish [Hadding-Koch and Studdert-Kennedy 1964], Hausa [Inkelas and Leben 1990], and Hungarian [Gósy and Terken 1994:278]. It has been observed in impressionistic studies of some Bantu languages, Zulu [Khumalo 1981:91], Zombo-Kongo [Carter 1973:300], Lingala [Guthrie 1970:37], Yao [Whiteley 1966:16], and Jita [Downing 1995:28].

In this paper, I present an instrumental study of these effects on fundamental frequency in Chichewa intonation. The paper is organized as follows. In Section 1, I present background information on Chichewa, and on the data and methodology of this study. In Section 2, I provide evidence of the effects of boundary tones on the fo realization of tones in Chichewa. In Section 3, I argue against an analysis of these effects in terms of a phonological representation of pitch register [Inkelas and Leben 1990], and for a model in which the effects are expressed in the phonetic interpretation of tones. In Section 4, I present evidence concerning the representation of the boundary tones in Chichewa, building on a proposal of Pierrehumbert and Beckman [1988]. Section 5 summarizes the results.

\section{Background}

1.1. Chichewa. Chichewa is the national language of Malawi, spoken as a first language by over half the population of Malawi and as a second language by another 25\% [Nelson 1975]. Intonation in Chichewa has been briefly described on an impressionistic basis by Louw [1987] and Kanerva [1989], but there have not been, to my knowledge, any previous instrumental studies of fundamental frequency in Chichewa. Indeed, the only such studies I know of for the Bantu family 
are Furere and Rialland [1985] for Kinyarwanda, and Odden [1994] for Kikerewe, neither of whom considers intonation. ${ }^{2}$ The only comprehensive study of intonation in a Bantu language is Maw and Kelly's [1975] impressionistic study of Swahili, a non-tone language. The present study is part of a larger on-going study of the f0 realization of tones in Chichewa.

1.2. Data. Six native speakers of Chichewa participated in the study. All six were students at Chancellor College at the University of Malawi who were paid for their assistance. Speaker JB is female, all others male. Speaker DB has Chiyao as a first language, but has spoken Chichewa as well since early childhood. All other speakers have Chichewa as their first language.

The speakers produced sets of mini-dialogues in which the same sentence was produced under different conditions: (a) as a statement or as a question; (b) with subject focus, object focus, or no focus; and (c) in utterance-final position, or nonfinally. The datasets were designed to give a preliminary overview of factors in Chichewa intonation, rather than to test any specific hypothesis.

The sentences were formulated with the help of the subjects to meet various conditions intended to facilitate f0 measurements. All words consisted entirely of sonorant consonants in order to avoid the distorting influence of obstruent phonation. All words had a high tone on the penultimate syllable. The sentences to be considered in the present study are given in (1):3
(1) a. Á-ma-yaján-a
3S-T-search
b. Mw-amúna á-ma-lamúl-a a-máyi
'He searches.'
man 3S-T-order woman
'The husband bosses around his wife.'
c. M-lámu w-á-m-நóno á-ma-yajan-ír-a a-máyi a-méne-wa 1-in-law 1-of-1-little 3S-T-watch-AP 2-woman 2-these
'The younger in-law supervises these women.'

One speaker read one role in the mini-dialogues while another speaker read the other role. They then switched roles.

Each sentence was produced as a question and as a statement in mini-dialogues such as the following. The underlined sentence is the test material that was analyzed in this study.

\footnotetext{
2 In contrast, there are now excellent instrumental studies of $\mathrm{fO}$ in a number of West African languages: Hausa [Inkelas and Leben 1990], Igbo [Liberman et al. 1993], and Yoruba [Connell and Ladd 1990, Laniran 1993].

3 Please excuse the sexist bias of the examples. The speakers unanimously balked at my efforts to introduce a bit more even-handed imagery.
} 
(2) a. A: Kođı mwamúna ámalamúla amávi?

Ques. man 3S-T-boss woman

'Does the man boss around the woman?'

B: Ée, mwamúna ámalamúla amáyi.

yes man 3S-T-boss woman

'Yes, the man bosses around the woman.'

b. A: Mwamúna ámalamúla amáyi.

man 3S-T-boss woman

'The man bosses around the woman.'

B: Zóóna? Mwamúna ámalamúla amávi? really man 3S-T-boss woman

'Really? The man bosses around the woman?'

Such data allow a comparison of intonation in questions versus statements.

There were also mini-dialogues for sentences (1b) and (1c) in which the sentence was produced non-finally, with material following it in the utterance, as in the examples in (3) below.

(3) A: Kodí mwamúna ámalamúla bambo wáke?

Ques.man 3S-T-boss father his

'Does the man boss his father?'

B: Íayi, mwamúna ámalamúla amáyi, ósatí bambo wáke?

no man 3S-T-boss woman not father his

'No, the man bosses around the woman, not his father.'

The answer in (3), unlike those in (2), is non-final in the utterance. These data were included to allow the comparison of final and nonfinal statements, and to determine the intonational effects of utterance-final position. ${ }^{4}$

In total, the mini-dialogues included 5 instances of sentence (1a) and 10 instances each of (1b) and (1c). The full dataset is given in the Appendix. Each subject played the A role twice and the B role twice. Thus, each speaker produced sentence (1a) 10 times, (1b) 20 times, and (1c) 20 times. Each speaker produced 12 question utterances and 38 statement utterances.

The recordings of these sessions were digitized and fundamental frequency contours were produced using the DOS-based pitch tracking system PLIB ('Phonology Laboratory In a Box'), which was designed by Anthony Woodbury

4 The position of focus was also systematically varied, as in (6) vs. (7) in the Appendix. But focus turned out to have no significant effect on $\mathrm{fO}$ and will not be taken into account here. 
and Kenneth Whistler on the basis of software by Mark Liberman and John McCarthy. This system is robustly noise-resistant, which was important for these recordings, since they were produced under less than perfect recording conditions in an office at the University of Malawi. Using the file editing tools in PLIB, I measured fO at local maxima and minima, and at the end of each phrase. The fO measurements for local maxima were the focus of this study. 5

\section{Results}

2.1. The Distribution of Boundary Tones. Two distinct pitch contours occurred at the end of phrases (i.e., sequences bounded by pauses). One was a fall to the speaker's lowest register, as at the end of (4a) and (4b), and the other was a sharp rise, as in (4c-d). The speaker is JB.

(4) a. Utterance-final statement (one phrase)

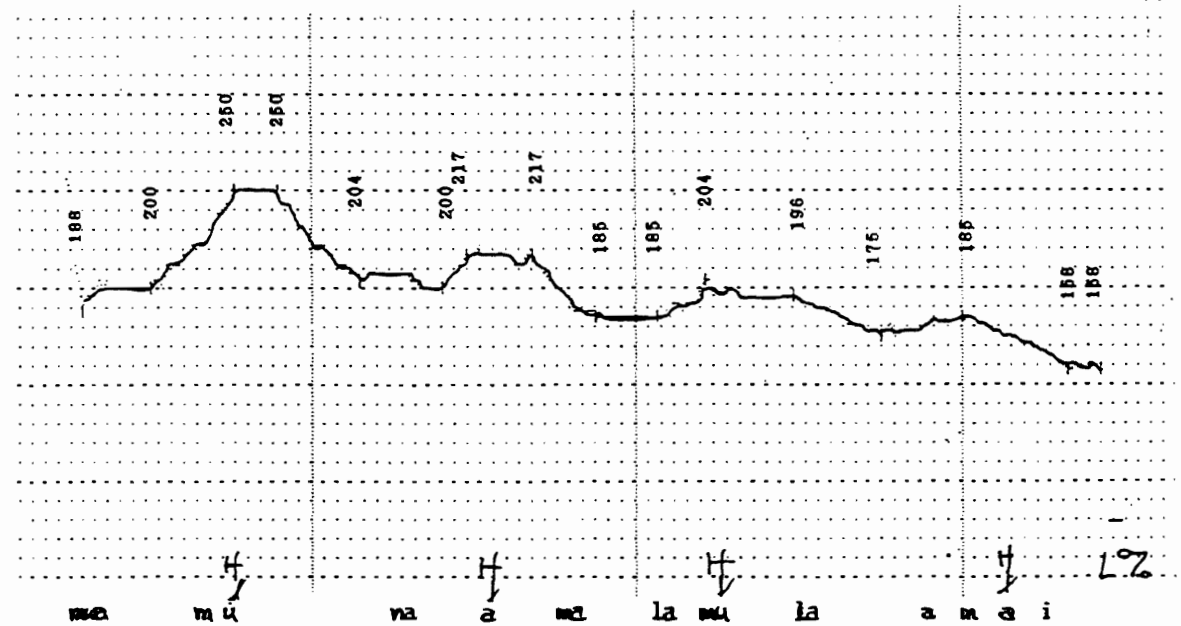

5 The $\mathrm{f} 0$ values of low-toned syllables were not included in the study, although they were measured. My current hypothesis is that low-toned syllables are actually toneless, and have no fo target [Stevick 1969]. One argument for this view is the fact that low tones play no role in Chichewa phonology. Things happen in Chichewa when there are high tones present, whereas low-toned forms are inert. Another argument is the fact that in phrases that are uttered quickly, alternating $\mathrm{HLH}$ sequences tended to be produced as a high plateau without a medial dip. This makes sense if the low-toned syllable is interpreted as a retum to default laryngeal configura-tion in the gap between targets (cf. the "catenary" interpolation described for English by Pierre-humbert [1980]), since at higher rates the toneless syllable would not form an appreciable gap between the high-toned targets. I am currently testing this hypothesis in an experiment in which the distance between peaks is systematically varied. 
b. Utterance-final statement (two phrases)

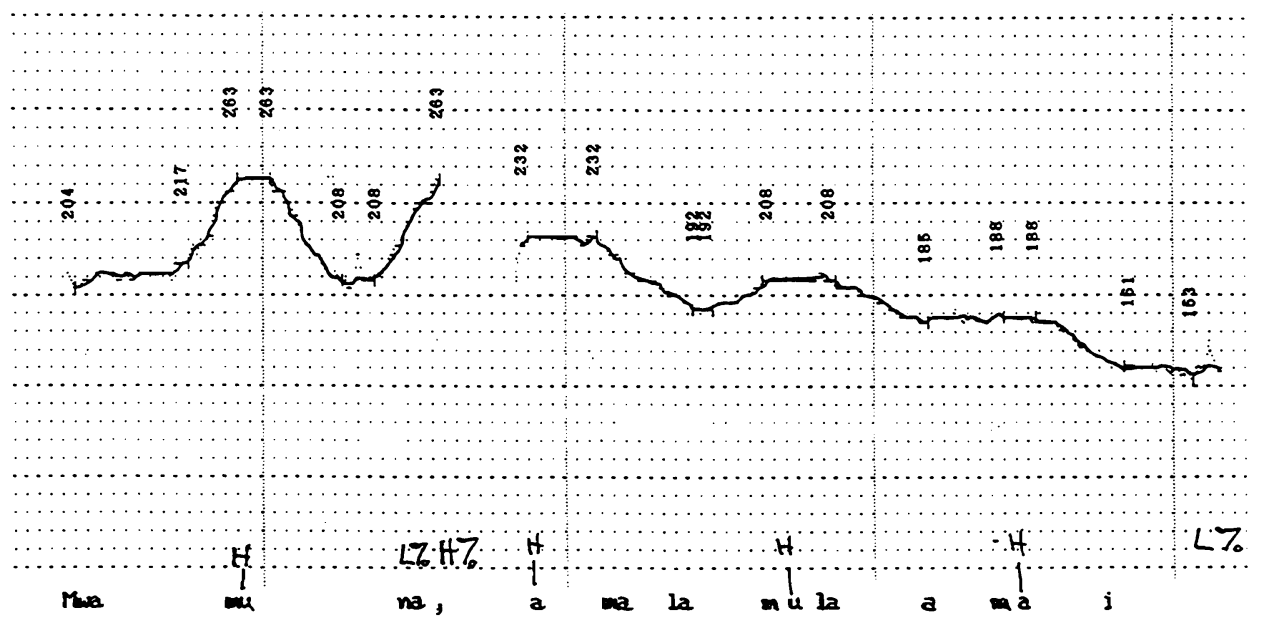

c. Question (one phrase)

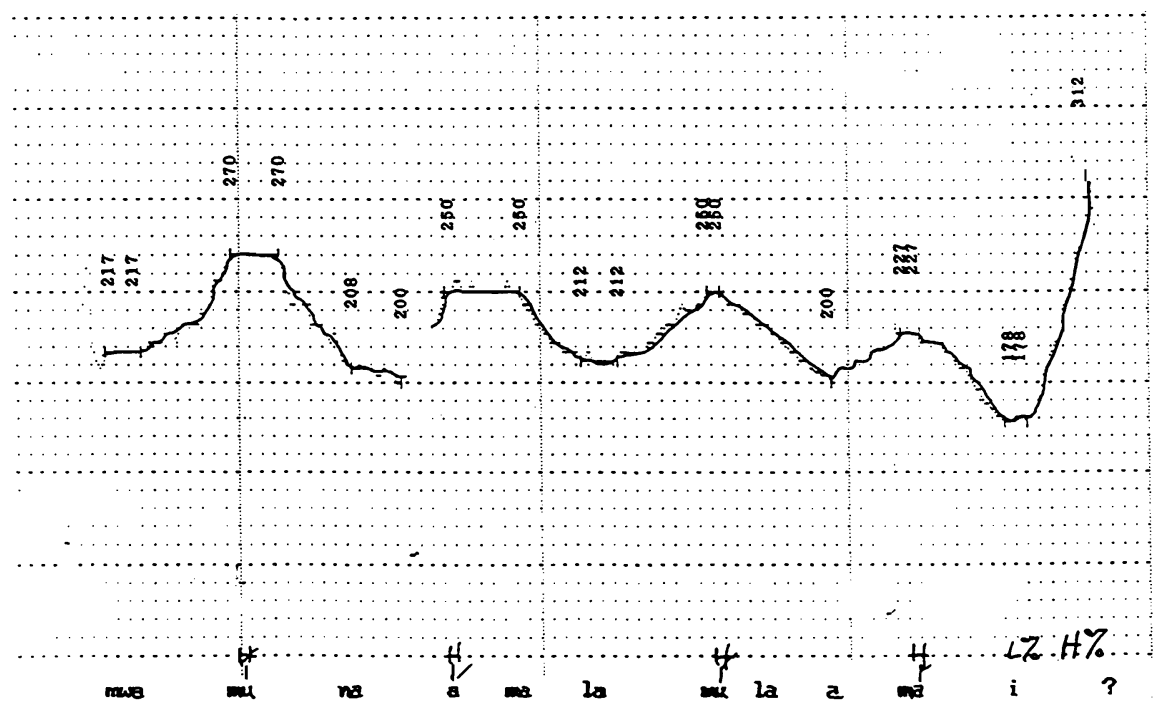


d. Nonfinal statement (two phrases)

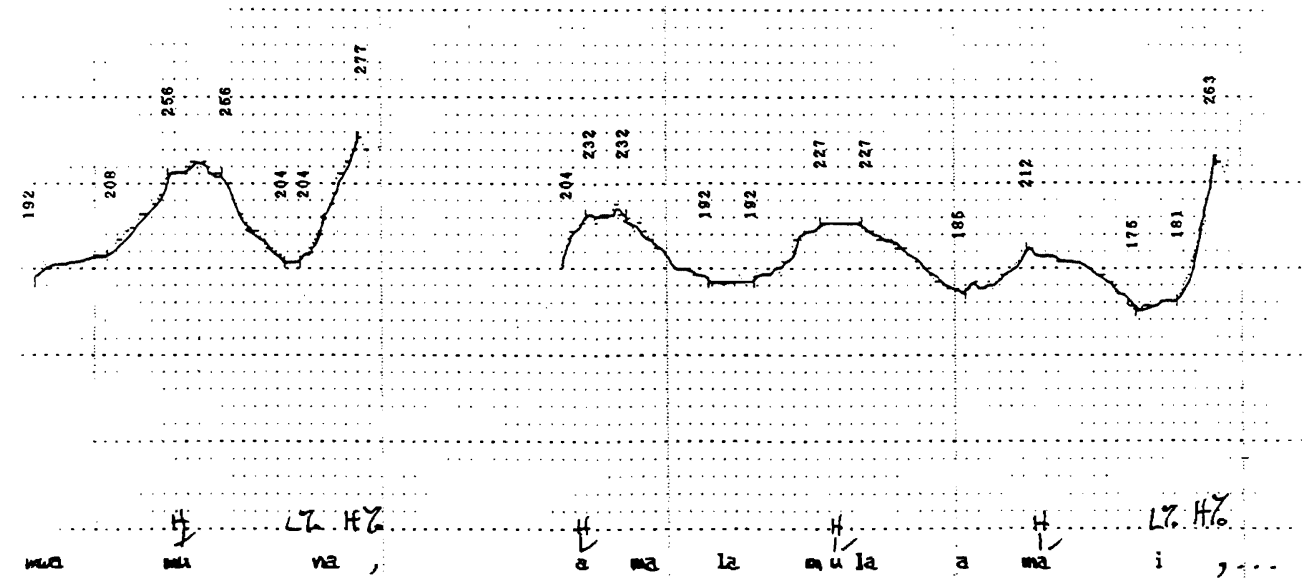

For all speakers, the final fall occurred at the end of every final statement, and the final rise occurred at the end of every question.

I interpret these final pitch excursions as the realization of boundary tones, i.e., intonational tones that are aligned with the edge of a phrase [Pierrehumbert 1980]. The final falls can be interpreted as the realization of a final boundary tone L\%, which is a low tone that is aligned with the final syllable of the phrase. Final rises can be interpreted as the realization of a final H\%. To account for the sharpness of the final rise, I assume that such rises actually have the sequence L\% $\mathrm{H} \%$ on the final syllable. Thus, every phrase has a final L\%, and some phrases have, in addition, $\mathrm{H} \%$ after $\mathrm{L} \%$.

Final L\% was the default for statements for all speakers. The distribution of $\mathrm{H} \%$ varied from speaker to speaker, as summarized in Table (5).

(5) Distribution of $\mathrm{H} \%$.

\begin{tabular}{|c|c|c|c|}
\hline Speaker & $\frac{\text { H\% at end of }}{\text { question }}$ & $\begin{array}{l}\text { H\% at end of } \\
\underline{\text { non-final clause }}\end{array}$ & $\begin{array}{l}\text { H\% after subject separated } \\
\text { from VP }\end{array}$ \\
\hline JB & always & always & usually \\
\hline PS & always & never & frequently \\
\hline SI & always & never & Iff object was focused \\
\hline hers & always & never & infrequently \\
\hline
\end{tabular}


For all speakers, $\mathrm{H} \%$ occurred at the end of every question. At the end of nonfinal statement clauses, as in (3) or (4d), speaker JB consistently had $\mathrm{H} \%$. All other speakers had L\% in this context.

In the longer sentences ( $1 \mathrm{~b})$ and (1c), the subject of the sentence was often separated from the rest of the sentence by a pause and a boundary tone (compare $4 \mathrm{~b}$ and $4 \mathrm{~d}$ ). For speakers JB and PS, this boundary tone was usually $\mathrm{H} \%$, as in (4b) and (4d). For speaker PS, the boundary was consistently L\% if the object was focused, and $H \%$ if the subject was focused. ${ }^{6}$ For all other speakers, the boundary tone of such a phrase was consistently L\%.

2.2. Effects of Boundary Tones on Downdrift. As can be seen in (4a), each successive high tone in a declarative phrase is realized at a lower fo than the preceding high tone. This is downdrift. As can be seen in the question (4c), there is less of a tendency toward downdrift in questions. For all speakers there was more downdrift in statements than in questions.

This trend can be seen in the graphs in (6), which represent the averaged f0 values for successive peaks in phrases with four high tones. On the $\mathrm{x}$-axis, $\mathrm{H} 1$ represents the average f0 value in Hertz for all high tones in initial position in a phrase, $\mathrm{H} 2$ the average f0 value for high tones that were in second position in the phrase, and so on. The circles represent the average values in questions, while the squares represent the values in statements.

(6) a.

\section{GS: Question vs. Statement Sequences}

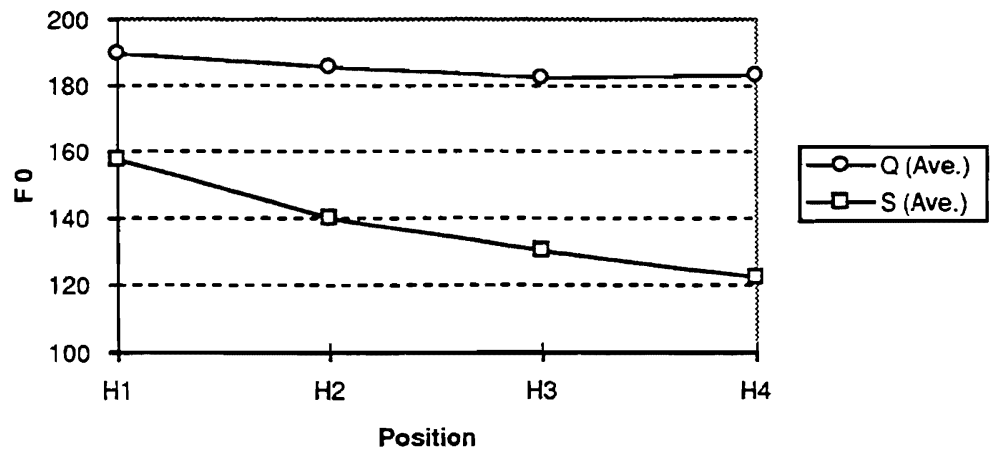

6 Bolinger [1978] argues that phrase-final rise has a general interpretation of incompleteness. Perhaps the H\% in PS's case be interpreted in this way as signalling that important information (i.e. the focus) is yet to come, while L\% announces that the presentation of new information is complete. 
(6) b.

JB: Question vs. Statement Sequences

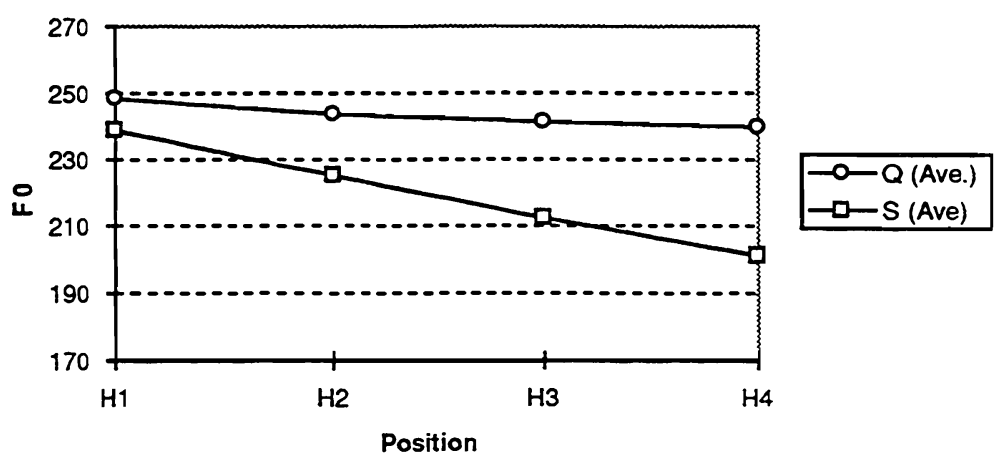

c.

\section{WM: Question vs. Statement Sequences}

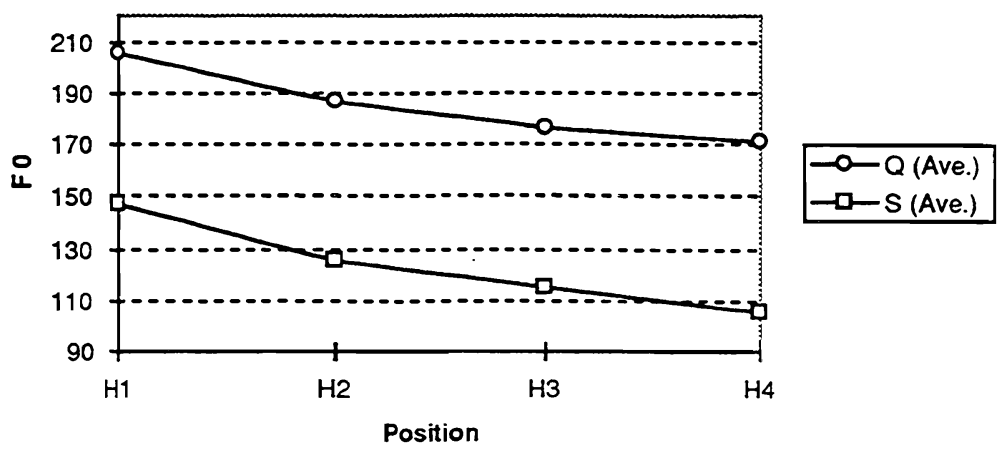


(6) d.

PS: Question vs. Statement Sequences

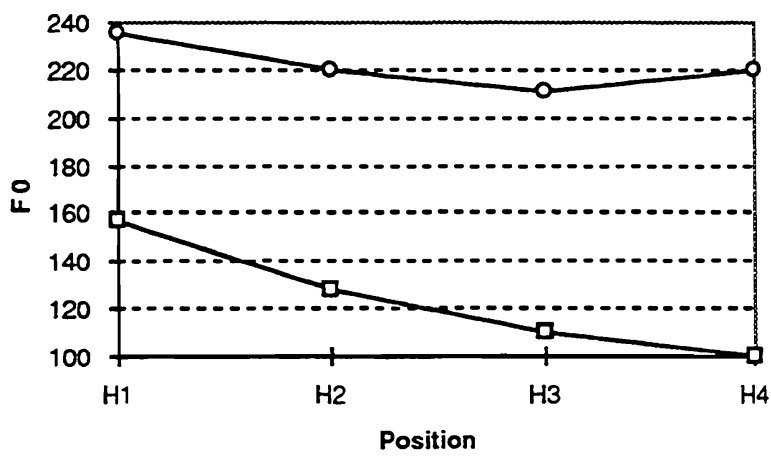

$$
\begin{aligned}
& -0-Q \text { (Ave.) } \\
& -0-S \text { (Ave.) }
\end{aligned}
$$

e.

\section{DB: Question vs. Statement Sequences}

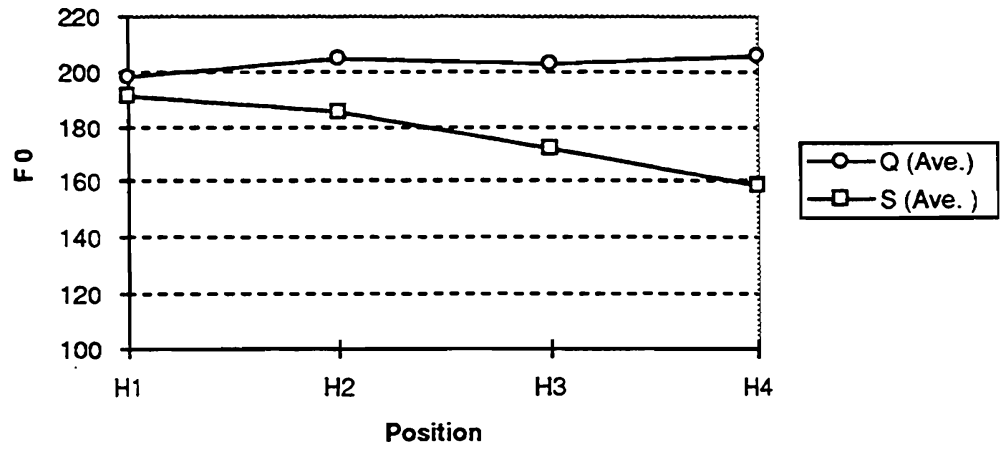


(6) $f$.

\section{SL: Question vs. Statement Sequences}

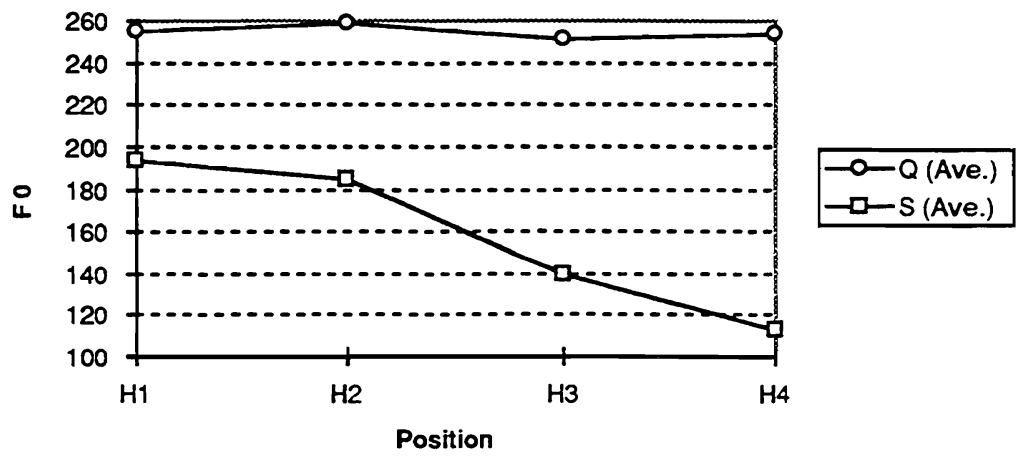

In all these graphs, the squares indicating peaks in statements slope downward more steeply than do the circles representing peaks in questions. For all speakers except for WM, the sequences in questions are close to horizontal, while the sequences in statements fall dramatically. Averaging across speakers, the mean fall in $\mathrm{f0}$ from the first high tone to the last in a phrase was $11 \mathrm{~Hz}$ in questions and $40 \mathrm{~Hz}$. in statements.

The same trend can be seen in graphs such as those in (7). The $\mathrm{x}$-axis in these graphs represents the $\mathrm{fO}$ value of the first of two successive high tones $\left(\mathrm{H}_{\mathrm{n}}\right)$, and the $y$-axis represents the f0 value of the second high tone in the sequence $\left(\mathrm{H}_{\mathrm{n}+1}\right)$. Thus, each point represents a sequence of two high tones in a phrase, and each such sequence is represented in the graphs. Statement datapoints are represented with squares, and question datapoints with circles. The line running through each set of datapoints is a regression line, which is the straight line that lies the smallest summed distance from all the datapoints. It represents the general trend in the datapoints: a dashed line for the question datapoints and a solid line for the statement datapoints. 
(7) a.

GS: Questions vs. Statements
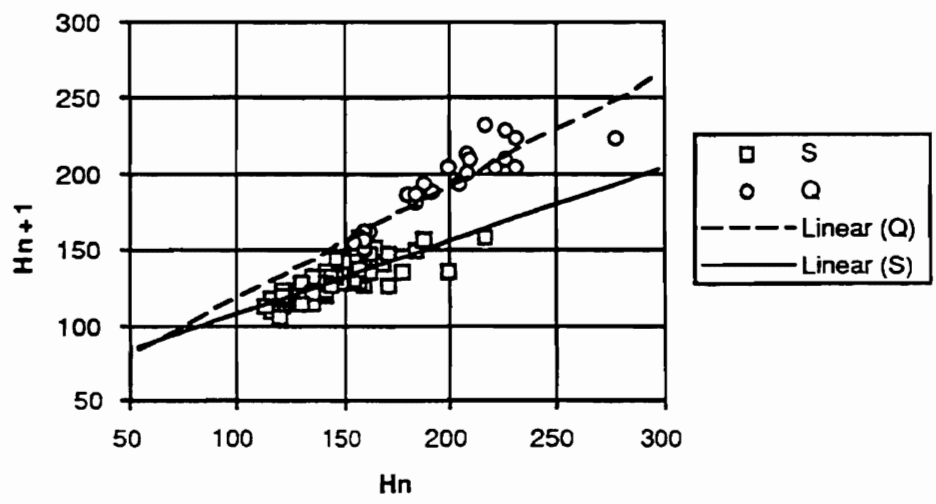

b.

JB: Questions vs. Statements
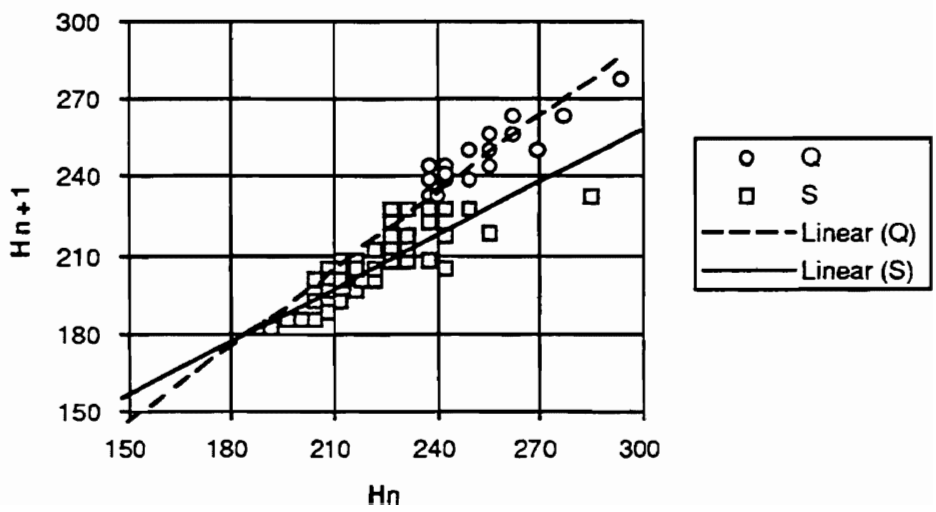
(7) c.

WM: Questions vs. Statements

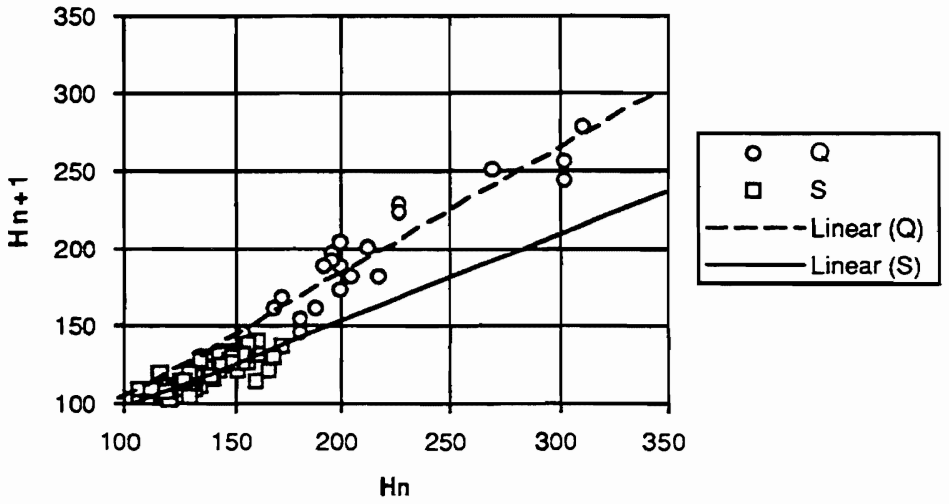

d.

PS: Questions vs. Statements

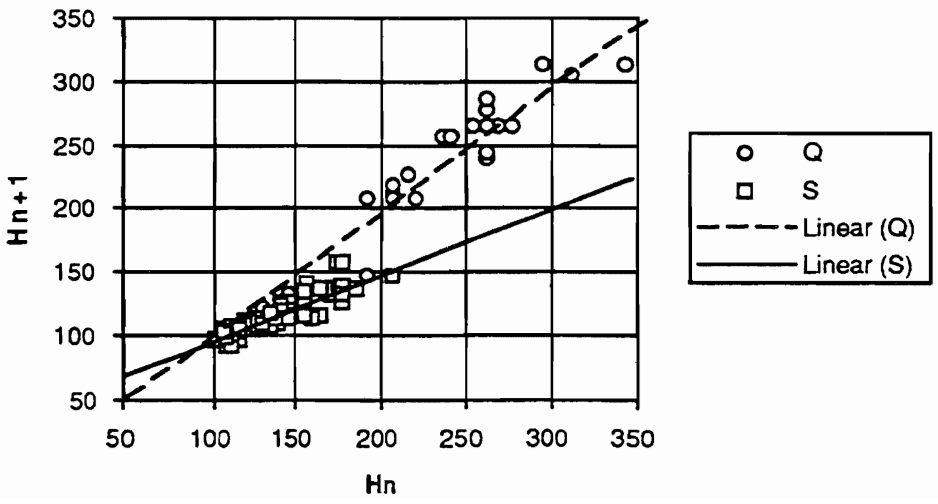


(7) e.

DB: Questions vs. Statements

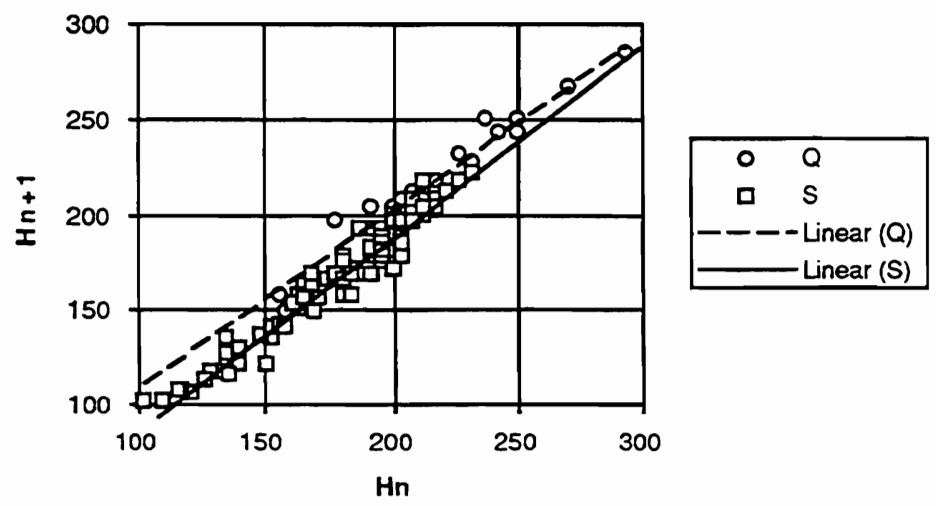

f.

\section{SL: Questions vs. Statements}

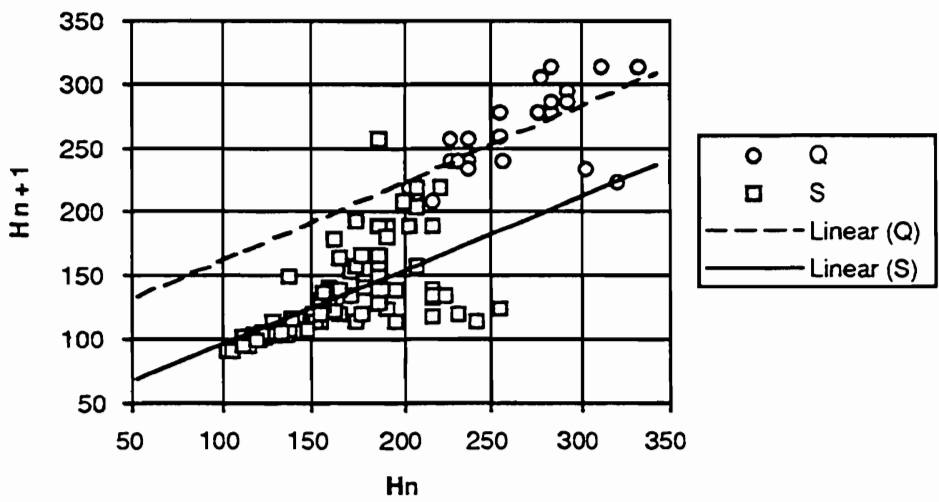

If successive high tones were realized at the same f0, the points in the graph would be clustered around the $x=y$ diagonal extending from the lower lefthand corner to the upper righthand corner. Instead, the solid regression line through the squares runs well below this diagonal. This indicates that in statements (represented by the squares), the second of two high tones is consistently lower than the first. The dotted regression line indicating the trend in questions, on the 
other hand, is closer to the $\mathrm{x}=\mathrm{y}$ axis, which means that in questions successive high tones are closer to being equal.

The degree of the downtrend can be expressed quantitatively through the quotient of $\mathrm{H}_{n+1}$ divided into $\mathrm{H}_{n}$, i.e., the second of two successive peaks divided into the first. The smaller $\mathrm{H}_{\mathrm{n}+1} / \mathrm{H}_{\mathrm{n}}$ is (i.e., the lower the second peak is relative to the first), the greater the downdrift effect. Such quotients for questions and statements are compared in (8).

(8)

\begin{tabular}{|c|c|c|c|}
\hline Speaker & $\begin{array}{l}\text { Mean } \mathrm{H}_{\mathrm{n}+1} / \mathrm{H}_{\mathrm{n}} \\
\text { in Statements }\end{array}$ & $\begin{array}{c}\text { Mean } H_{n+1} / H_{n} \\
\text { in Questions }\end{array}$ & $T$ test \\
\hline GS & .90 & .97 & $\mathrm{p}<.001$ \\
\hline JB & .93 & .98 & $\mathrm{p}<.001$ \\
\hline WM & .88 & .92 & $\mathrm{p}<.01$ \\
\hline PS & .85 & .99 & $\mathrm{p}<.001$ \\
\hline SL & .81 & .99 & $\mathrm{p}<.001$ \\
\hline $\mathrm{DB}$ & .93 & 1.01 & $\mathrm{p}<.001$ \\
\hline
\end{tabular}

The quotient is consistently lower in statements than in questions, indicating that there is more downdrift in statements.

To test whether this difference is statistically significant, we perform t-tests, which tell us the probability of finding such a difference by chance given the size and variability of our sample. The result ' $p<.001$ ' given in the last column of (8) indicates that for that speaker the odds are greater than $99.9 \%$ that the difference would still be there if we were able to measure every question and every statement that that speaker ever produced. 7 Downdrift is significantly greater in statements than in questions in Chichewa. ${ }^{8}$

2.3. Pitch range. The pitch range in questions in Chichewa is higher than in statements. This can be seen in (6) in the clear layering of the question sequences above the statement sequences. It can be seen in (7) in the fact that the question

7 The result "p $<.01$ " for speaker WM sets the odds at $99 \%$, which is still above the usual standard (95\%) for statistical significance. For all comparisons of questions to statements in this paper, I used a two-tailed t-test assuming unequal variances.

I have assumed in this analysis that the quotients of the different sequences in a sentence are independent, e.g., that $\mathrm{H} 2 / \mathrm{H} 1$ is independent from $\mathrm{H} 3 / \mathrm{H} 2$. The quotients do not seem to be more similar within a sentence than between sentences. However, I also did a t-test using just the first sequence $\mathrm{H} 2 / \mathrm{H} 1$ for each sentence, so that there was only one observation per utterance. The difference in downdrift between statements and questions was still significant at the .01 level for all speakers except WM, for whom it was significant at the .05 level.

8 Surprisingly, focus had no effect on f0 for any speaker except SL. The quotient $\mathrm{H}_{n+1} / \mathrm{H}_{n}$ where $\mathrm{H}_{\mathrm{n}+1}$ is focused was not significantly different for any speaker from the ratio for unfocused $\mathrm{H}_{\mathrm{n}+1}$. SL, however, did have different boundary tones depending on focus (compare (5)), and sporadically had dramatic raising of $\mathrm{H}$ in the focused phrase. 
datapoints cluster above and to the right of the statement datapoints, indicating that both $\mathrm{H}_{n}$ and $\mathrm{H}_{\mathrm{n}+1}$ tend to be higher in questions. A simple quantitative measure of this effect is the mean of the fo peaks in statements and in questions, as in (9).

(9)

\begin{tabular}{llccc} 
& Speaker & $\begin{array}{c}\text { Mean fO of } \mathrm{H} \\
\text { in Statements }\end{array}$ & $\begin{array}{c}\text { Mean fO of } \mathrm{H} \\
\text { in Questions }\end{array}$ & \multicolumn{1}{c}{ T test } \\
a. GS & 136 & 193 & $\mathrm{p}<.001$ \\
b. JB & 216 & 251 & $\mathrm{p}<.001$ \\
c. & WM & 128 & 205 & $\mathrm{p}<.0001$ \\
d. PS & 125 & 246 & $\mathrm{p}<.001$ \\
e. & SL & 150 & 264 & $\mathrm{p}<.001$ \\
f. & DB & 172 & 219 & $\mathrm{p}<.001$
\end{tabular}

Each number in the second column represents the average of all the f0 values for high-toned syllables in statements for one speaker, and the numbers in the third column represent the same for questions. The average fo value for $\mathrm{H}$ is much higher in questions than in statements. This difference is statistically significant for all speakers.

However, we might expect the average value for $\mathrm{H}$ to be higher in questions just because the values don't decline as much over the course of the phrase. Thus, if both questions and statement began in the same pitch range, downdrift in statements might by itself bring the mean fo value of high tones in statements down below that in questions.

To show that the pitch range is indeed higher in questions than in statements even aside from the difference in downdrift, we consider in (10) the average f0 values of the initial $\mathrm{H}$ in the phrase. ${ }^{9}$

$\begin{array}{lccc}\quad \text { Speaker } & \begin{array}{c}\text { Mean f0 of first } \\ \text { H in Statements }\end{array} & \begin{array}{c}\text { Mean f0 of first } \\ \text { H in Questions }\end{array} & \frac{T \text { test }}{206} \\ \text { a. GS } & 159 & 235 & \mathrm{p}<.001 \\ \text { b. JB } & 235 & 259 & \mathrm{p}<.001 \\ \text { c. WM } & 150 & 233 & \mathrm{p}<.001 \\ \text { d. PS } & 153 & 261 & \mathrm{p}<.001 \\ \text { e. SL } & 178 & 271 & \mathrm{p}<.001 \\ \text { f. DB } & 182 & 223 & \mathrm{p}<.01\end{array}$

${ }^{9}$ Another reason to do this test is that we might question whether the different high-toned syllables in the same phrase are really independent observations-a necessary condition for the t-test. See fn. 7 . 
The fo level of $\mathrm{H}$ is significantly higher in questions than in statements already in the first $\mathrm{H}$ of the phrase. Thus, the difference in downdrift cannot account for the difference in average $\mathrm{fO}$ values of $\mathrm{H}$ between questions and statements.

We conclude that the pitch range is higher in questions than in statements in Chichewa.

2.4. Clause Type Effects Are Due to Boundary Tones. So far we have only compared questions to statements. For most speakers in the study, questions were the only clauses ending in $\mathrm{H} \%$, and all statements ended in L\%. Speaker JB, however, consistently had $\mathrm{H} \%$ at the end of nonfinal statement clauses, marking a continuing utterance, as in (4d). These nonfinal statements were intermediate between questions and nonfinal statements in their degree of downdrift and the mean $\mathrm{fO}$ value of $\mathrm{H}$, as seen in (11). 10

\section{(11) Speaker JB}
Nonfinal
Final
Statement Statement
ANOVA
a. Downdrift:
Question
.96
.93
$F(2,109)=26.10$
$\mathrm{p}<.01$
b. Mean $\mathrm{f} 0$ of
$\mathrm{H}(\mathrm{Hz})$
251
222
215
$\mathrm{F}(2,48)=13.49$
$\mathrm{p}<.01$

Non-final statements had a higher value for $\mathrm{H}_{n+1} / \mathrm{H}_{\mathrm{n}}$ than final statements, indicating that they had less downdrift. Non-final statements also had a higher mean $\mathrm{fO}$ value for $\mathrm{H}$ than in final statements. In both measures, non-final statements had lower values than in questions. Both three-way distinctions were statistically significant at the .01 level according to a single factor ANOVA (a generalization of the t-test for comparison of more than two groups).

Non-final statements are declarative statements just like final statements. The crucial difference between final and non-final statements in JB's speech is that the latter have a final rise. This is also the crucial difference between JB's non-final statements and those of the other speakers. None of the other speakers had $\mathrm{H} \%$ at the end of non-final statements, and none of them had significant differences in downdrift or pitch range between final and non-final statements.

10 Most speakers had a $\mathrm{H} \%$ rise at the end of the subject in at least some cases. My impression is that the high tones in such subjects had less downdrift and higher pitch range than subjects with final L\%, as expected. But these phrases were so rapid that the individual high tones could not be distinguished, and they were not included in the analysis. 
I conclude that the downdrift and pitch range effects are conditioned not by the syntactic or semantic distinction between declarative and question clause types, but rather by the identity of the final boundary tone. There is significantly less downdrift in $\mathrm{H} \%$-final phrases (questions and nonfinal statements) than in L\%-final ones (final statements), and the pitch range is higher in $\mathrm{H} \%$-final phrases than in L\%-final ones.

\section{Models}

We have seen that final boundary tones have a significant effect on the f0 values of lexical tones in Chichewa. There are two fundamentally different ways to represent such a pattern: it can be encoded in the phonological representation, or it can be expressed in the phonetic implementation of the representation. The phonological analysis is appropriate in cases of categorical distinctions, while the phonetic implementation analysis is appropriate for gradient pattems. One of the key issues in contemporary phonetics and phonology is how to distinguish the two kinds of pattern [Pierrehumbert 1980, Pierrehumbert and Beckman 1988, Cohn 1993].

In this section, we consider three different ways of representing the boundary tone effects. In Sections 3.1, we consider a model in which the trends are encoded in the phonological representation, while in Section 3.2 two quantitative models are presented in which the fo trends are expressed in the phonetic implementation of tones. We conclude that the effects are better expressed in terms of phonetic implementation.

3.1. A Phonological Model. In an important series of papers on $\mathrm{f} 0$ in Hausa, Leben, Inkelas, and Cobler report that, as we have found in Chichewa, the pitch range is higher in questions that in statements, and that downdrift occurs in statements but not in questions [Inkelas, Leben, and Cobler 1987; Leben, Inkelas and Cobler 1989; Inkelas and Leben 1990]. They argue that in order to capture the two correlated effects, a representation of register must be built into the phonological representation.

They propose that the basic lexical tone distinction be represented in terms of $\mathrm{H}$ vs. $\mathrm{L}$ on the primary tone tier. Contrasts in pitch range, on the other hand, are represented with $\mathrm{H}$ and $\mathrm{L}$ on another tier-the register tier. The two tiers are both associated to a class node, the tonal root node. Register $\mathrm{H}$ is interpreted as a higher relative pitch range and register $L$ is interpreted as a lower relative pitch range. The primary tones are interpreted as high or low values within the specified pitch range. The question morpheme, which conditions raising of pitch range, is represented as in (12a) with a register $\mathrm{H}$. A downstepped high tone, on the other hand, is represented as in (12b) with a register L. 
(12) a. Question morpheme

b. Downstepped H

$\begin{array}{clc}\text { L } & \text { Primary tone tier } & \text { H } \\ \text { I } & \text { I } \\ \text { O } & \text { Tonal root node } & \text { O } \\ \text { I } & \text { I } \\ \text { H } & \text { Register tier } & \text { L }\end{array}$

The pitch range effects are expressed through three processes, as presented in (13) [Inkelas, Leben and Cobler 1987:331; Inkelas and Leben 1990:23-4].

(13) a. Register High Insertion:

If there is a register $\mathrm{H}$ in the phrase, it is copied onto each preceding primary $\mathrm{H}$ in the phrase.

b. Register Low Insertion:

If there is a primary low tone, assign it a register $\mathrm{L}$.

c. Downdrift:

Spread register $\mathrm{L}$ onto primary $\mathrm{H}$, unless it already has a register tone from (a).

These phonological rules have the result that every primary $\mathrm{H}$ in a phrase with a register $\mathrm{H}$ (e.g., a question) is assigned a register $\mathrm{H}$, and all other primary high tones are assigned a register $\mathrm{L}$. The former will therefore be interpreted at a higher pitch range than the latter. Furthermore, if a register $L$ is interpreted as inducing iterative lowering of the register, phrases without register $\mathrm{H}$ (e.g., statements) will show downdrift. Inkelas and Leben [1990] argue that this model provides an alternative to models of phonetic implementation of tone such as Liberman and Pierrehumbert [1984] and Pierrehumbert and Beckman [1988].

One problem with this proposal is methodological. In the phonetic implementation models it is meant to replace, representations are mapped to fo values, which can then be checked against the actual values. In the phonological model, on the other hand, the only information provided about the phonetic interpretation of the representations is in terms of vague descriptions such as "raise the register". It is therefore impossible to test the predictions of this model with the same rigor as those of quantitative models.

Another problem is that nothing in the model predicts the correlation of high pitch range with lack of downdrift. To get downdrift, we must interpret the register $L$ in (12b) as "lower the pitch range from the previous value". But the interpretation of register $\mathrm{H}$ cannot be to raise the pitch range from the previous value, since otherwise each successive register $\mathrm{H}$ would induce another raising, leading to an upward staircase of $\mathrm{f} 0$ in high register phrases. The interpretation of register $\mathrm{H}$ must therefore be something like "go to the 'high' pitch range", 
regardless of the previous value. The pitch range effect and the downdrift effect are separate properties in the implicit fo interpretation of the two different register tones. The model gives no reason to expect the two effects to occur together.

Third, the phonological analysis in (13) requires that assimilation on the register tier be represented through copy. This runs contrary to the crosslinguistic evidence that assimilation is better represented through spread [e.g., Hayes 1986]. Copying is an operation requiring transformational power, and it always leads to a violation of the Obligatory Contour Principle [Yip 1988]. An analysis that avoids the use of tone copy is therefore to be preferred, all else being equal.

3.2. Quantitative Models. As Liberman and Pierrehumbert [1984] show, the general shape of the downdrift curve is that of a decaying exponential to a nonzero asymptote. The decline in f0 is greater after higher fo values than after lower fo values, so that the decline flattens out as it approaches the bottom of the pitch range.

A very simple model of downdrift reflecting this fact can be given as in (14), based on Liberman and Pierrehumbert's [1984] model for English.

(14) $H_{n+1}-r=d *\left(H_{n}-r\right)$

$H_{n}$ represents the fo value of the first of two successive high tones, and $H_{n+1}$ represents the fo value of the second. We use the equation to determine $\mathrm{H}_{n+1}$ on the basis of $\mathrm{H}_{\mathrm{n}}$. The variable $r$ is a speaker-dependent fo value representing the bottom of the speaker's (current) pitch range. It is the non-zero asymptote that declining fo values approach but do not reach. The coefficient $d$ is a number between 0 and 1 representing the downdrift factor. If $d$ is one, then each successive high tone has exactly the same fo as the preceding one. If $d$ is less than one, on the other hand, each successive high tone is rendered lower than the previous one by a constant proportion, relative to the baseline. With $r$ and $d$ specified, such an equation can be applied iteratively to predict $\mathrm{f} 0$ values for the noninitial peaks in an utterance, given the fo value of the first peak.

We will consider two classes of such models. In the first, the $\mathrm{D}$ models, the difference in downdrift between $\mathrm{H} \%$-final and L\%-final phrases is expressed in

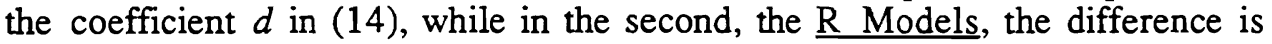
reflected in the value of the asymptote $r$.

3.2.1. D Models. In the D models, $r$ was held constant for a given speaker. It was calculated by averaging the values of utterance-final L\% for that speaker as an estimate of the speaker's baseline. The value for $d$, on the other hand, differed 
depending on the final boundary tone. It was higher in questions than in statements, reflecting the difference in downdrift.

For each speaker, models were constructed according to the formula in (14). Given the fo value of the first high tone in the utterance, the equation was applied iteratively, yielding predicted values for each of the following high tones. These values were then compared to the actual values in terms of the absolute errorthe absolute value of the difference between the actual and the predicted value. The goal was to find the setting for $d$ for each speaker that minimized the mean of the absolute errors.

In (15), the resulting models are summarized by presenting the values of the crucial constants $d$ and $r$ for each speaker. The relative success of each model is indicated by the mean absolute error, given both in $\mathrm{Hz}$, and as a percentage of the range of that speaker (the difference between that speaker's highest and lowest recorded fo values).

\begin{tabular}{|c|c|c|c|c|c|}
\hline & Speaker & $\underline{r}$ & $\underline{d}$ & $\begin{array}{l}\text { Mean absolute } \\
\text { error }(\mathrm{Hz})\end{array}$ & $\begin{array}{c}\text { Mean absolute } \\
\text { error } \\
\text { (\% of range) }\end{array}$ \\
\hline a. & GS & 115 & $\begin{array}{l}.48(\mathrm{~S}) \\
.95(\mathrm{Q})\end{array}$ & 6.74 & 3.6 \\
\hline b. & $\mathrm{JB}$ & 160 & $\begin{array}{l}.97(\mathrm{~S}) \\
.78(\mathrm{SC}) \\
.87(\mathrm{Q})\end{array}$ & 6.89 & 4.3 \\
\hline c. & WM & 100 & $\begin{array}{l}.51(\mathrm{~S}) \\
.85(\mathrm{Q})\end{array}$ & 7.05 & 3.2 \\
\hline d. & PS & 90 & $\begin{array}{l}.52(\mathrm{~S}) \\
.97(\mathrm{Q})\end{array}$ & 7.06 & 2.7 \\
\hline e. & SL & 86 & $\begin{array}{l}.61(\mathrm{~S}) \\
.99(\mathrm{Q})\end{array}$ & 19.8 & 7.6 \\
\hline f. & $\mathrm{DB}$ & 96 & $\begin{array}{l}.89(\mathrm{~S}) \\
1.0(\mathrm{Q})\end{array}$ & 8.61 & 3.6 \\
\hline
\end{tabular}

For speaker GS, for example, the f0 of each successive pitch peak was predicted through iterative application of the equation $\mathrm{H}_{\mathrm{n}+1}-115=.48 *\left(\mathrm{H}_{\mathrm{n}}-115\right)$ if the utterance was a statement, or the equation $\mathrm{H}_{\mathrm{n}+1}-115=.95 *\left(\mathrm{H}_{\mathrm{n}}-115\right)$ if it was a question. Compared to the actual f0 values, this model was off by an average of $6.74 \mathrm{~Hz}$, which is less than $4 \%$ of GS's total pitch range.

The D models are more successful for some speakers than for others, but for all but speaker SL, the predicted value differs from the actual value by an average less than $5 \%$ of the speaker's pitch range. This is close enough to suggest that the relation among successive fo peaks is regular and determinate. These 
models are reasonably successful in capturing the difference in downdrift between questions and statements in the data.

However, the models do not capture the fact that the pitch range is higher in questions than in statements. The only thing that distinguishes questions from statements in these models is the downdrift coefficient $d$, so they would lead one to expect that differences in downdrift are the only differences in f0 between questions and statements. They therefore miss a significant pattern distinguishing questions from statements in the data.

3.2.2. R Models. Inkelas and Leben [1990] point out the importance of capturing the correlated distinctions in downdrift and pitch range between questions and statements. In this section we present a model of phonetic implementation that builds on these insights, while defining an explicit mapping to f0 values.

The model arises out of the observation that downdrift is not in fact completely absent in $\mathrm{H} \%$-final phrases in Chichewa. In particular, questions that begin especially high often have a fairly sharp fall at the beginning, but then level off at a relatively high level (e.g., (4c)). This suggests that it is the bottom of the pitch range, the asymptote $r$ of the downdrift curve, that is affected by the final boundary tone. The effects of varying $r$ while holding $d$ constant are illustrated in (16).

The Effects of Varying $R$

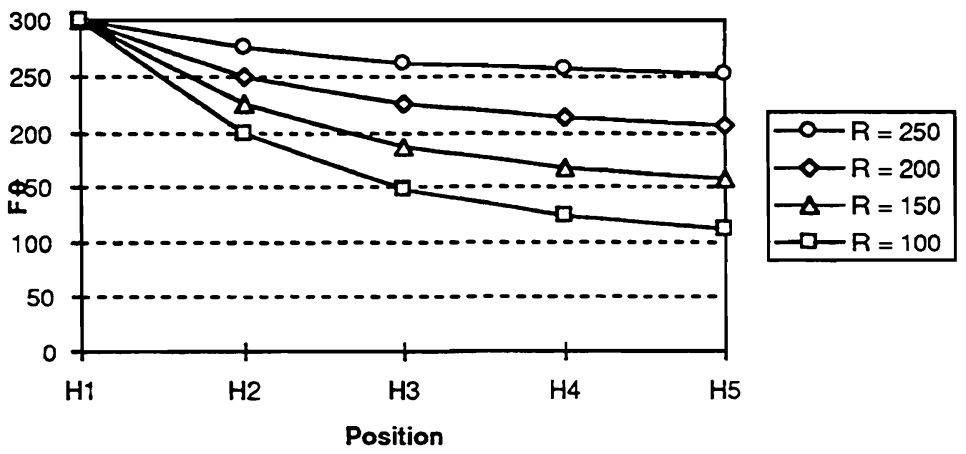

For each curve in (16), the value of the initial peak is $300 \mathrm{~Hz}$ and the downstep factor is .50. The curves differ just in the value of $r$. Notice that as $r$ gets larger, the curves get flatter and higher. When $r$ is 250 , for example, there is only a 50 $\mathrm{Hz}$ fall from $\mathrm{H} 1$ to $\mathrm{H} 5$, and all $\mathrm{f} 0$ values are above $250 \mathrm{~Hz}$. When $r$ is 100 , on the 
other hand, there is a $200 \mathrm{~Hz}$ fall from $\mathrm{H} 1$ to $\mathrm{H} 5$, and $\mathrm{fO}$ values extend down to almost $100 \mathrm{~Hz}$. A high $r$ puts a high bottom limit on $\mathrm{f} 0$ values and on the downward trend in f0, while a low $r$ allows low f0 values and further continuation of the f0 downtrend. Thus, manipulating $r$ while holding $d$ constant has the desired effect of capturing the correlation of downdrift effects with pitch range effects.

To test the plausibility of such a model, the optimal value for the aymptote $r$ was calculated independently for each utterance. The downdrift coefficient $d$ was held constant for each speaker at the average value for that speaker. I then determined the value of $r$ that minimized the mean absolute error for each utterance. Table (17) gives the means of these asymptotes for each clause type.

(17) Mean $r$ asymptote values $(\mathrm{Hz})$

\begin{tabular}{|c|c|c|c|}
\hline Speaker & Questions & Statements & $\begin{array}{l}\text { Nonfinal } \\
\text { Statements }\end{array}$ \\
\hline GS & 182 & 118 & \\
\hline b. JB & 226 & 167 & 188 \\
\hline c. WM & 144 & 100 & \\
\hline d. PS & 176 & 100 & \\
\hline SL & 252 & 87 & \\
\hline $\mathrm{DB}$ & 223 & 119 & \\
\hline
\end{tabular}

It can be seen that the mean values of the asymptote are considerably higher in questions than in statements. For speaker JB, with a three-way distinction, the value of $r$ was higher in questions than in non-final statements, and higher in nonfinal statements than in final statements. Thus, the asymptote was higher in phrases ending in $\mathrm{H} \%$ (questions, and JB's non-final statements) than in phrases ending in L\% (final statements, and non-final statements for speakers other than $\mathrm{JB})$.

We see then that $r$ does, indeed, vary as a function of the boundary tone. A model that reflects this is one in which the downstep factor $d$ is held constant for a given speaker, and the pitch range baseline $r$ varies with the boundary tone. The results of this sort of model are summarized in (18). The constants for each speaker are given together with the mean absolute error. The mean absolute error is small in these models when compared to the whole pitch range. These models perform quite well, then, in predicting the f0 value of peaks. 
(18)

\begin{tabular}{|c|c|c|c|c|c|}
\hline & Speaker & $\underline{r}$ & $\underline{d}$ & error $(\mathrm{Hz})$ & (\% of range) \\
\hline a. & GS & $\begin{array}{l}115(\mathrm{~S}) \\
185(\mathrm{Q})\end{array}$ & .5 & 7.78 & 4.2 \\
\hline b. & JB & $\begin{array}{l}238(\mathrm{Q}) \\
195(\mathrm{SC}) \\
168(\mathrm{~S})\end{array}$ & .75 & 6.72 & 4.2 \\
\hline c. & WM & $\begin{array}{l}100(\mathrm{~S}) \\
118(\mathrm{Q})\end{array}$ & .75 & 12.18 & 5.5 \\
\hline d. & PS & $90(S, Q)$ & .95 & 15.71 & 5.9 \\
\hline e. & SL & $\begin{array}{r}86(\mathrm{~S}) \\
272(\mathrm{Q})\end{array}$ & .6 & 20.08 & 7.7 \\
\hline & $\mathrm{DB}$ & $\begin{array}{l}115(\mathrm{~S}) \\
227(\mathrm{Q})\end{array}$ & .85 & 8.95 & 3.8 \\
\hline
\end{tabular}

If we compare the performance of these models to the D models in (15), we find a somewhat mixed picture. The $\mathrm{R}$ model performs slightly better for speaker JB, but the D models are slightly better for all other speakers. The difference is not very great; the average difference in mean absolute error between the two models is $2.5 \mathrm{~Hz} .11$

On the other hand, the R models capture the pitch range effect as well as the downdrift effect. The constant $r$ represents the bottom of the current pitch range, so the $\mathrm{f} 0$ value of the first $\mathrm{H}$ in a phrase must be above $r$, and $\mathrm{f} 0$ cannot go below $r$ during that phrase. Thus, the $\mathrm{R}$ models, unlike the $\mathrm{D}$ models, correctly predict that pitch range is higher in questions than in statements.

The $\mathrm{R}$ models do not have the shortcomings found in the phonological model discussed in Section 3.1. First, the R models include an explicit phonetic interpretation, so that their empirical success can be evaluated objectively. Second, the $R$ models capture the correlation of downdrift and pitch range effects in terms of the single constant $r$. Third, the R models do not require the representation of tone assimilation as copy. The correlation of downdrift and pitch range effects thus does not support the phonological representation of downtrends.

11 One factor affecting the performance of the $\mathrm{R}$ models might be the the fact that overall loudness was not controlled in this study. Liberman and Pierrehumbert [1984] find that in English speaking more loudly is reflected in fo by raising of the pitch range baseline. Loudness varied randomly in this study, which could affect $r$ in a way orthogonal to the boundary tone effect. I am currently investigating this possibility in a study on the effects of variation in loudness on $\mathrm{fO}$ in Chichewa. 


\section{The Representation of Boundary Tones}

A boundary tone is a tone that marks the edge of a prosodic category, such as an intonational phrase. Pierrehumbert and Beckman (1988) propose that a boundary tone is autosegmentally associated with that prosodic category. The $\mathrm{H} \%$ in (19), for example, is a boundary tone for the prosodic category "minor phrase" (MP), and this status is represented by associating the tone with the MP node itself (though it can also be associated with a syllable).

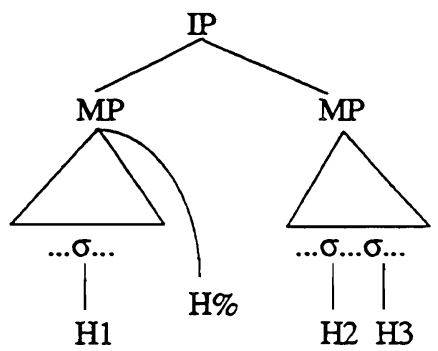

In this representation, $\mathrm{H} 1$ is only a property of the syllable it is associated with, but $\mathrm{H} \%$ is to be interpreted as a property of the whole MP.

One argument in favor of this representation concerns locality in phonetic implementation. We have seen that the identity of the final boundary tone affects the f0 interpretation of every tone in the phrase. In contrast, the identity of later lexical tones is irrelevant to the f0 interpretation of earlier lexical tones. It would seem then that the identity of the boundary tone must be accessible during the phonetic interpretation of every tone in the phrase in a way that the identity of other lexical tones is not.

This makes sense given the Pierrehumbert-Beckman representation because the boundary tone is a property of the whole phrase. $\mathrm{H} 1$ in (19) is associated with a syllable that is a constituent of MP, and MP is associated with H\%. The domains of $\mathrm{H} 1$ and $\mathrm{H} \%$ thus overlap. We can say that the interpretation of any lexical tone depends on (a) its phonological identity, (b) the phonological identity and f0 value of the preceding tone, and (c) the phonological identity of the tones of any dominating categories.

I would like to further propose that the boundary tones are on a tier distinct from the lexical tone tier. This is suggested in (19) by the misalignment of the boundary tone $\mathrm{H} \%$ with the lexical tones $\mathrm{H} 1, \mathrm{H} 2$, and $\mathrm{H} 3$. The basic intuition is that a tier is a string of temporally ordered elements (McCarthy 1989). A boundary tone associated with a prosodic phrase cannot be on the same tier as lexical tones within that phrase, since the dominating phrase cannot be ordered with respect to its constituent tone-bearing syllables. 
The argument for the separation of the boundary tone tier from the lexical tone tier comes from the transparency of medial $\mathrm{H} \%$. Where the subject was separated from the predicate by a pause, there was often a $\mathrm{H} \%$, indicated by a final f0 rise (e.g., as in 4b,d). Interestingly, neither the pause nor the $\mathrm{H} \%$ affected the general pattern of downdrift among the surrounding lexical high tones. Consider the instances of configuration (19) in the speech of speaker JB.

\section{(20) Speaker JB: ....H1 L $\quad$ H\% $\mathrm{H}_{2} \quad \mathrm{~L} \quad \mathrm{H}_{3} \ldots$}

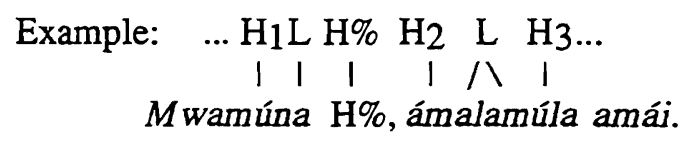
a. Mean $\mathrm{H} 2 / \mathrm{H} 1=.96$
Mean $\mathrm{H} 3 / \mathrm{H} 2=.95$
T-test: $\mathrm{p}>.05$
b. Mean $\mathrm{H} 2 / \mathrm{H} \%=.85$
Mean $\mathrm{H} 3 / \mathrm{H} 2=.95$
T-test: $\mathrm{p}<.01$

The mean $\mathrm{H} 2 / \mathrm{H} 1$ quotient in (20a) represents the degree of downdrift between the first two lexical high tones. The difference between the $\mathrm{H} 2 / \mathrm{H} 1$ quotients and the $\mathrm{H} 3 / \mathrm{H} 2$ quotients is very small (.01), and is not statistically significant. This means that the intervening $\mathrm{H} \%$ does not affect the degree of downdrift, since downdrift is the same after $\mathrm{H} \%$ as it is before.

On the other hand, there is a significant difference between $\mathrm{H} 2 / \mathrm{H} \%$ and $\mathrm{H} 3 / \mathrm{H} 2$, as in (20b). Thus, $\mathrm{H} \%$ is not included in the same downdrift curve that includes the lexical high tones $\mathrm{H} 2$ and $\mathrm{H} 3$. Together with the lack of difference between $\mathrm{H} 2 / \mathrm{H} 1$ and $\mathrm{H} 3 / \mathrm{H} 2$, this supports the conclusion that the fo interpretation of the lexical high tones is unaffected by an intervening boundary $\mathrm{H} \%$.

This transparency makes sense if the lexical tones and boundary tones are on separate tiers. The f0 value of $\mathrm{H} 2$ in (19) is calculated as a function of the f0 value of the preceding tone on the same tier $(\mathrm{H} 1)$, and the dominating boundary tone of the second MP. H\% is the immediately preceding tone in time, but it plays no role in the calculation because it is on a different tier.

\section{Conclusion}

The intonation of questions in Chichewa differs in three ways from that in statements. Questions end in a final rise, have little downdrift, and have a higher pitch range than in statements. Statements end in a final fall, have a strong downdrift trend in successive high tones, and have a lower pitch range than in questions.

The relation among the fo values of successive high tones is regular and can be modelled quantitatively. Given the fo value of the first tone in an utterance, it is possible to predict the f0 values of later high tones with a fair degree of accuracy. 
In the R-Models, the effects of the boundary tone were captured through manipulation of the bottom limit $r$ of the pitch range. This accounts for both the relative lack of downdrift in questions, and the higher pitch range.

This set of Chichewa data also provides evidence supporting the representation of boundary tones as dependents of prosodic phrases, as proposed in Pierrehumbert and Beckman [1988]. Boundary tones have influence on the f0 interpretation of every tone in the phrase they belong to. They are also transparent in the fo interpretation of flanking lexical tones, suggesting that they should be represented on a separate tier.

\section{Appendix: Materials}

$A$ and $B$ indicate roles in the mini-dialogues. Underlined stretches were those that were included in the measurements presented in this paper.

I. Sentence \#1

(1) A: Kodi Question 3S-T-watch

'Does s/he watch?'
B: Ée, ámayanána. yes 3S-T-watch
'Yes, s/he watches.'

(2) A: Ámayanána.
'S/-T-watch
S/hatches.'

B: Zóóna? ámayanána?
really
'Really? S/he watches?'

(3) A: Ámachíta chíyaní lówéruka liri lonsé? 3S-T-do what Saturday which-is every 'What does s/he do every Saturday?'

B: Ámayanána. he/she-watches 'S/he watches.'

II. Sentence \#2

(4) A: Kođŕ mwamúna ámalamúla amáyi? Ques. man 3S-T-boss woman 'Does the man boss around the woman?'

(5) A: Mwamúna ámalamúla amáyi. man 3S-T-boss woman 'The man bosses around the woman.'

(6) A: Kodí mwamúna ámalamúla yaní? Ques.man 3S-T-boss who 'Who does the man boss around?'

(7) A: Kođı́ ndaní ámalamúla amáyi? Ques. who 3S-T-boss woman 'Who bosses around the woman?'
B: Ée, mwamúna ámalamúla amáyj. yes man 3S-T-boss woman 'Yes, the man bosses around the woman.'

B: Zóóna? Mwamúna ámalamúla amávi? really man 3S-T-boss woman 'Really? The man bosses around the woman?'

B: Mwamúna ámalamúla amáyi. man 3S-T-boss woman 'The man bosses around the woman.'

B: Mwamúna ámalamúla amáyi. man 3S-T-boss woman 'The man bosses around the woman.' 
(8) A: Kođi mwamúna ámalamúla bambo wáke? Ques.man 3S-T-boss father his 'Does the man boss around his father?'

(9) A: Kođi mwaná wawó ámalamúla amáyi? Ques. child her 3S-T-boss woman 'Does her child boss around the woman?'
B: Íyayi, mwamúna ámalamúla amáyi. no man 3S-T-boss woman 'No,the man bosses around the woman.'

B: Íyayi, mwamúna ámalamúla amáyi. no man 3S-T-boss woman 'No,the man bosses around the woman.'

(10) A: Kodí mwamúna ámalamúla bambo wáke? Ques.man 3S-T-boss father his 'Does the man boss around his father?'

B: Íyayi, mwamúna ámalamúla amáyi, ósatí bambo wáke. no man 3S-T-boss woman not father his 'No,the man bosses around the woman., not his father.'

(11) A: Kodí mwaná wawó ámalamúla amáyi? Ques. child her 3S-T-boss woman 'Does her child boss around the woman?'

B: Íyayi, mwamúna ámalamúla amáyi. ósati mwaná wawó. no man 3S-T-boss woman not child her 'No,the man bosses around the woman, not her child.'

III. Sentence \#3

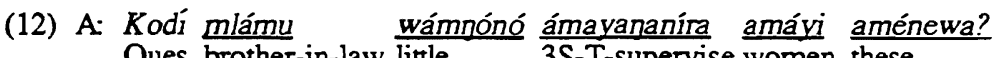
Ques. brother-in-law little 3S-T-supervise women these 'Does the younger brother-in-law supervise these women?'

B: Ée, mlámu wámnónó ámayananira amáyi aménewa? yes brother-in-law little 3S-T-supervise women these 'Yes, the younger brother-in-law supervises these women.'

(13) A: Mlámu wámnónó ámayananira amáyi aménewa. brother-in-law little 3S-T-supervise women these 'The younger brother-in-law supervises these women.'

B: Zóóna? Mlámu wámnónó ámayananira amáyi aménewa? really brother-in-law little 3S-T-supervise women these 'Really? The younger brother-in-law supervises these women?'

(14) A: Kodí mlámu wámıónó ámayananira yaní? Ques. brother-in-law little 3S-T-supervise who 'Who does the younger brother-in-law supervise?'

B: Mlámu wámpónó ámayananira amáyi aménewa. brother-in-law little 3S-T-supervise women these 'The younger brother-in-law supervises these women.' 
(15) A: Kodí ámayananíra amáyi aménewa?

Ques. 3S-T-supervise women these

'Who supervises these women?'

B: Mlámu wámnónó ámayananira amáyi aménewa. brother-in-law little 3S-T-supervise women these

'The younger brother-in-law supervises these women.'

(16) A: Kodi mlámu wámjónó ámayajaníra ántchíto awo? Ques. brother-in-law little 3S-T-supervise women these 'Does the younger brother-in-law supervise those workers?'

B: Íyayi, mlámu . wámnónó ámayananíra amáyi aménewa. no brother-in-law little 3S-T-supervise women these 'No, the younger brother-in-law supervises these women.'

(17) A: Kodi mkázi wámkúlu ámayananíra amáyi aménewa? Ques. woman big 3S-T-supervise women these 'Does the senior woman supervise these women?'

B: Íyayi, mlámu wámnónó ámayananira amáyi aménewa. no brother-in-law little 3S-T-supervise women these 'No, the younger brother-in-law supervises these women.'

(18) A: Kodí mlámu wámgónó ámayajaníra ántchíto awo? Ques. brother-in-law little 3S-T-supervise women these 'Does the younger brother-in-law supervise those workers?'

B: Íyayi, mlámu . wámnónó ámayananira amáyi aménewa, ósatí ántchíto awo. no brother-in-law little 3S-T-supervise women these not workers those 'No, the younger brother-in-law supervises these women, not those workers.'

(19) A: Kodí mkázi wámkúlu ámayananíra amáyi aménewa? Ques. woman big 3S-T-supervise women these 'Does the senior woman supervise these women?'

B: Íyayi, mlámu wámnónó ámayananira amávi aménewa ósati mkázi wámkúlu. no brother-in-law little 3S-T-supervise women these not womanbig 'No, the younger brother-in-law supervises these women, not the senior woman.'

\section{References}

Bolinger, Dwight. 1978. Intonation Across Languages. In Joseph Greenberg (ed.), Universals of Human Language, Volume 2: Phonology. pp. 471-524. Stanford, Ca.: Stanford University Press. 
Carter, Hazel. 1973. Syntax and Tone in Kongo. London: SOAS.

Cohn, Abigail. 1993. Nasalization in English: Phonology or Phonetics. Phonology 10: $43-82$.

Connell, Bruce and D. Robert Ladd. 1990. Aspects of Pitch Realization in Yoruba. Phonology 7: 1-29.

Downing, Laura. 1995. The Metrical Domain of Register Raising in Jita: An Optimality Approach. In Francis Katamba (ed.), Bantu Phonology and Morphology, pp. 28-39. Munich: LINCOM Europa.

Furere, R. and Annie Rialland. 1985. Tons et accents en kinyarwanda. In Didier Goyvaerts (ed.), African Linguistics, pp. 99-166. Amsterdam: John Benjamins.

Gårding, Eva. 1987. Speech Act and Tonal Pattern in Standard Chinese: Constancy and Variation. Phonetica 44: 13-29.

Gósy, Mária and Jacques Terken. 1994. Question Marking in Hungarian: Timing and Height of Pitch Peaks. Journal of Phonetics 22: 269-281.

Guthrie, Malcolm. 1967. Comparative Bantu. London: Gregg International.

Guthrie, Malcolm. 1970. Tone Ranges in a Two-Tone Language (Lingala). Collected Papers on Bantu Linguistics, pp. 33-44. London: Gregg International.

Hadding-Koch, Kerstin and Michael Studdert-Kennedy. 1964. An Experimental Study of Some Intonation Contours. Phonetica 11: 175-185.

Hayes, Bruce. 1986. Inalterability in CV Phonology. Language 62: 321-352.

Inkelas, Sharon and William Leben. 1990. Where Phonology and Phonetics Intersect: The Case of Hausa Intonation. In John Kingston and Mary Beckman (eds.), Papers in Laboratory Phonology I: Between the Grammar and the Physics of Speech, pp. 17-34. Cambridge: Cambridge University Press.

Inkelas, Sharon, William Leben, and Mark Cobler. 1987. The Phonology of Intonation in Hausa. In Joyce McDonough and Bernadette Plunkett (eds.), Proceedings of NELS 17:.327-341. Amherst, MA: GLSA. . 
Kanerva, Jonni. 1989. Focus and Phrasing in Chichewa Phonology. New York: Garland Press.

Khumalo, J. S. 1981. Zulu Tonology, Part 1. African Studies 40: 53-131.

Laniran, Yetunde. 1993. Intonation in Tone Languages: The Phonetic Implementation of Tones in Yoruba. Ithaca: Cornell Linguistics Publications.

Leben, William, Sharon Inkelas, and Mark Cobler. 1989. Phrases and Phrase Tones in Hausa. In Paul Newman and Robert Botne (eds.), Current Approaches to African Linguistics, Vol. 5. pp. 45-61. Dordrecht: Foris.

Liberman, Mark and Janet Pierrehumbert. 1984. Intonational Invariance Under Changes in Pitch Range and Length. In Mark Aronoff and Richard Oehrle (eds.), Language Sound Structure, pp. 157-233. Cambridge: MIT Press.

Liberman, Mark, J. Michael Schultz, Soonhyun Hong and Vincent Okeke. 1993. The Phonetic Interpretation of Tone in Igbo. Phonetica 50: 147-160.

Louw, J. K. 1987. Chichewa: A Practical Course. Pretoria: UNISA.

Maw, Joan and John Kelly. 1975. Intonation in Swahili. London: SOAS.

McCarthy, John. 1989. Linear Order in Phonological Representation. Linguistic Inquiry 20: 71-100.

Nelson, Harold (ed.). 1975. Area Handbook for Malawi . Washington, D.C.: American University.

Odden, David. 1994. Tone Spread in Kikerewe. Paper given at the 25th Annual Conference on African Linguistics, Rutgers University.

O'Shaughnessy, Douglas. 1979. Linguistic Features in Fundamental Frequency Patterns. Journal of Phonetics 7: 119-145.

Pierrehumbert, Janet. 1980. The Phonetics and Phonology of English Intonation. Bloomington: Indiana University Linguistics Club.

Pierrehumbert, Janet and Mary Beckman. 1988. Japanese Tone Structure. Cambridge: MIT Press.

Rycroft, David. 1963. Tone in Zulu Nouns. African Language Studies 4: 43-68. 
Stevick, Earl. 1969. Tone in Bantu. International Journal of American Linguistics 35: $330-341$.

Thorsen, Nina. 1978. An Acoustical Investigation of Danish Intonation. Journal of Phonetics 6: 151-175.

Uldall, Elizabeth. 1962. Ambiguity: Question or Statement? or 'Are You Asking Me or Telling Me?'. In A. Sovijärki and P. Aalto (eds.), Proceedings of the Fourth International Congress of Phonetic Sciences., pp. 770-83. The Hague: Mouton.

Whiteley, W. H. 1966. A Study of Yao Sentences. London: Oxford University Press.

Yip, Moira. 1988. The OCP and Phonological Rules: A Loss of Identity. Linguistic Inquiry 19: 65-100.

Department of Linguistics The University of Texas Calhoun Hall 501 Austin, TX 78712

s.myers@mail.utexas.edu
[Received May 3, 1996; provisional acceptance July 2, 1996; final version accepted August 28, 1996] 